\title{
Artelogie
}

Recherche sur les arts, le patrimoine et la littérature de l'Amérique latine

$4 \mid 2013$

Fêtes et célébrations en Amérique latine

\section{"São os farrapos que voltam" : o heroísmo farroupilha entre o passado e o futuro do Rio Grande do Sul}

\section{Camila Silva}

\section{(2) OpenEdition}

Edição electrónica

URL: https://journals.openedition.org/artelogie/6118

DOI: 10.4000/artelogie.6118

ISSN: 2115-6395

Editora

Association ESCAL

Refêrencia eletrónica

Camila Silva, «"São os farrapos que voltam" : o heroísmo farroupilha entre o passado e o futuro do Rio Grande do Sul», Artelogie [Online], 4 | 2013, posto online no dia 02 fevereiro 2013, consultado o 01 dezembro 2021. URL: http://journals.openedition.org/artelogie/6118; DOI: https://doi.org/10.4000/ artelogie.6118

Este documento foi criado de forma automática no dia 1 dezembro 2021.

Association ESCAL 


\title{
"São os farrapos que voltam" : o heroísmo farroupilha entre o passado e o futuro do Rio Grande do Sul
}

\author{
Camila Silva
}

“As populações sem memoria voltam-se para as proprias origens do seu ser, procurando, na

trepidação de suas iras, o mysterio de sua proeminencia. O gaúcho, entretanto, para sentir os avós-centauros que estiveram no Seival e no Fanfa, basta apoiar-se do seu cavallo impaciente, olhar o recorte de sua paisagem amada, abaixarse num gesto de afago ao chão de sua patria, e collar a orelha a essa terra abençoada : ouvirá um longinquo estremer de canhadas, sacudidas por inviziveis cavallarias... Silencio então ! São os farrapos que voltam !" Pedro Calmon. Heróes e Terra. Correio do Povo, Porto Alegre, 20 set. 1935, s/p (Edição Farroupilha).

\section{Apresentação}

1 Ao tratar da história do Rio Grande do Sul, pode-se considerar a Revolução Farroupilha como um dos episódios mais repercutidos na sociedade sul-rio-grandense. A cada 20 de setembro, porto-alegrenses de todas as idades preparam-se para a comemoração deste evento. Sentindo-se peões ou prendas, citadinos pilcham-se com seus chiripás, guaiacas, ceroulas, saias de armação, vestidos e bombachinhas. A cavalo ou a pé, andam pelas ruas da capital, entre prédios e carros, em sua maior parte carregando o chimarrão. Assistem ao passado sendo encenado no desfile farroupilha, e passeiam 
entre os piquetes e o fogo de chão no Parque Harmonia. Não é necessário o uso do vocábulo gaúcho para que os elementos acima citados sejam relacionados à imagem mental que se guarda desta figura típica ${ }^{1}$. Enquanto alguns eventos exigem o esforço interpretativo do historiador para serem trazidos a luz como tal, a Revolução Farroupilha parece estar cristalizada como um dos "fatos históricos evidentes" ${ }^{2}$ do passado sul-rio-grandense. (ELMIR, 2004: p. 23) Partindo, portanto, de um terreno aparentemente sólido, pretende-se debater a construção de uma memória farroupilha, considerando o que foi proposto por Albuquerque Jr. "É vasculhando as camadas constitutivas de um dado saber, de um dado acontecimento, de um dado fato, que podemos apreender o movimento de seu aparecimento (...)". (ALBUQUERQUE JR., 2007 : p. 151) Para tanto, propõe-se uma análise das narrativas comemorativas do primeiro Centenário Farroupilha, presentes nos jornais A Federação, Correio do Povo, Diário de Notícias e Jornal da Manha $\tilde{a}^{3}$. O contexto comemorativo, em sua efemeridade, "se apresenta como reescritura da história e atualização do passado", que "não remete somente a um fato, mas à sua interpretação"

2 Comemorar, portanto, significa também re-apresentar "uma coisa ausente", isto é, uma versão sobre o ocorrido, e não o acontecimento em si mesmo. (CHARTIER, 1990 : p. 20) Elaborada pelo presente, a memória de um evento pode ter muito mais a dizer sobre aqueles que criam, organizam e selecionam as lembranças, do que sobre o passado em questão. Assim, tendo a comemoração do Centenário Farroupilha - e não o evento que está sendo comemorado - como objeto, discute-se alguns significados atribuídos ao próprio presente, na medida em que este confere sentidos ao passado. $O$ trabalho aproxima-se ao projeto historiográfico defendido por Guimarães, voltado para a articulação dos domínios da "política, cultura histórica e uma história das formas de lembrar-

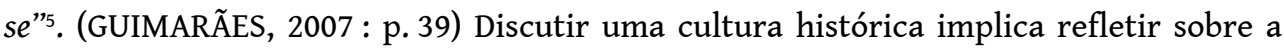
maneira como uma sociedade administra o seu passado e lida com a temporalidade. Também, como afirma Le Goff, a cultura histórica pode ser compreendida como a mentalidade histórica de uma época, ou, "a relação que uma sociedade, na sua psicologia coletiva, mantém com o passado". (LE GOFF, 2003 : p. 48) Nesta vertente, investigam-se quais foram as marcas das re-presentificações e usos do passado farroupilha no contexto comemorativo em questão. Dentre as possibilidades de trabalho, optou-se por abordar neste texto a construção de uma memória heroica sobre os personagens farroupilhas e seus desdobramentos.

\section{Os heróis (do passado) : o panteão farroupilha nas páginas dos jornais}

Guardadas as diferentes características editoriais, os jornais analisados apresentam em seu conteúdo uma galeria de nomes relacionados à Revolução Farroupilha. Dos textos que narraram determinados episódios da epopeia, até as ilustrações de alguns dos personagens vinculados a este evento, formaram-se representações que compunham o panteão farroupilha. Conforme Nora, "quanto mais grandiosas fossem as origens tanto mais elas nos tornariam maiores. Somos nós que somos venerados através do passado." (NORA, 1984 : p. 31) De acordo com o autor, busca--se aqui identificar a partir de quais elementos as narrativas criaram possibilidades para que o presente pudesse reconhecer-se no passado. 
Figura 1 - Imagem de David Canabarro

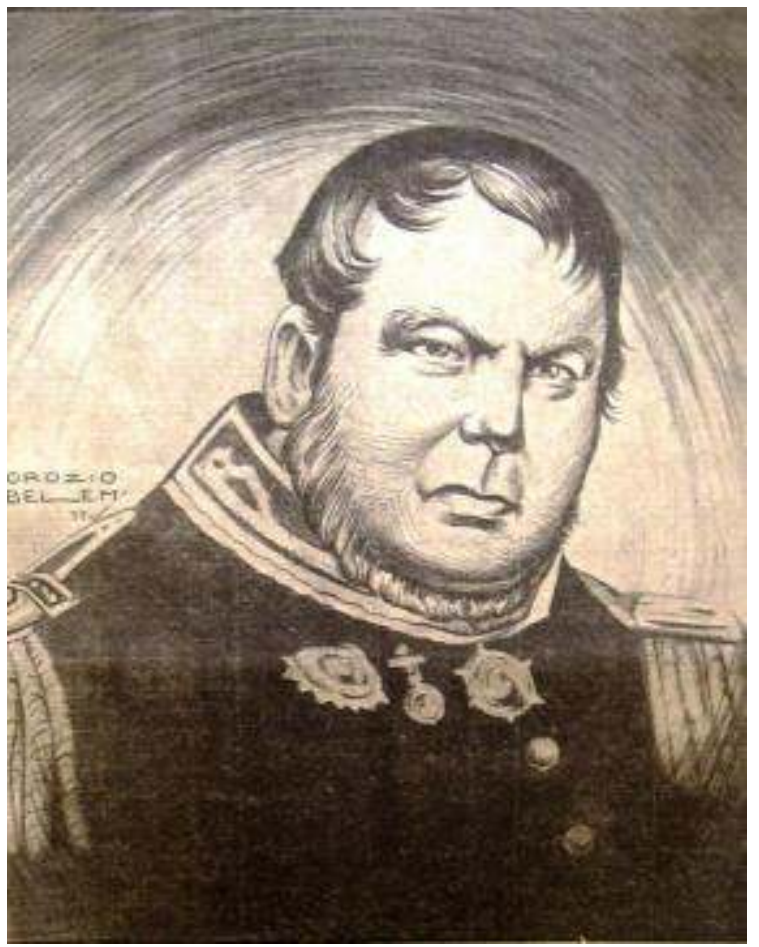

Diário de Notícias. Porto Alegre, 20 set. 1935

Museu de Comunicação Social Hipólito José da Costa

4 A edição comemorativa do Centenário Farroupilha publicada pelo Diário de Notícias apresentou uma sequência dos notáveis farrapos, estando entre eles a figura do general David Canabarro [figura 1]. o componente militar, a aparência aguerrida e a expressão de hombridade, presentes na imagem, acordam com o texto que a segue, da autoria de Othelo Rosa.

5 Na descrição do autor, David Canabarro surge como um "homem volumoso espadaudo, de olhar semi-cerrado, em que transluz perenemente uma chama de malicia alegre". Aliada aos atributos físicos, o autor aponta também a vocação para a guerra: "o guerreiro gaucho tem qualquer coisa de sobrehumano. A sua tenacidade é prodigiosa. A sua energia assombra. 0 seu tino militar espanta". Para o Othelo Rosa, tais atributos eram manifestações de um "tipo rio-grandense", comum a todos os gaúchos : "n'um resumo fiel, as qualidades nativas da gente gaucha, estruturada nesse panorama fisico e moral, para todo o sempre perdido, do aspero e belo Rio Grande de antanho". (ROSA, 1935 : s/p)A distinção com que o autor envolve a imagem de Canabarro, baseia-se na ascendência açoriana do general. Exaltando os valores deste personagem, o autor escreve que: "Ele tem face a face do perigo, na visinhança da morte, aquela perenidade perfeita, augusta, que foi, no riograndense de ontem, traço fundamental e marcante. Do açoriano, de que provinha, ele guardava a devoção do dever, aquele brio antigo de cumprir pontualmente a obrigação, [...]. A sua vontade é modelada em aço : e ele sabe manter, o que é uma tradição de raça, na asperesa de seu feito, lealmente aos seus companheiros, fidelidade inviolavel nos seus compromissos".

6 A origem étnica está aqui como um dos elementos unificadores de um tipo regional, que, na visão do autor, fez dos farrapos "uma geração predestinada". (ROSA, 1935 : s/p) Ao mesmo tempo em que a narrativa relaciona o arquétipo do rio-grandense à imagem heroica dos farroupilhas, procura identificá-la como um símbolo da nação. Para Othelo 
Rosa, graças a "força poderosa de um instinto" os farrapos foram predestinados a serem os "precursores da ideologia federativa no Brasil", [...] martires concientes e incomparaveis de um anseio que se estratificara nas camadas profundas da nacionalidade". (ROSA, 1935: s/ p)Dentre os nomes recordados pela edição comemorativa do jornal Correio do Povo, chama a atenção o destaque conferido ao de Bento Gonçalves da Silva. A descrição minuciosa de Virgilio Várzea ${ }^{6}$ sobre o farroupilha edifica a figura de um homem forte : "alto (segundo o pesquisador Alfredo Ferreira Rodrigues) medindo 1,79 conforme verificou, pelo proprio esqueleto do heroe. [...] sadio, robusto, sem ser volumoso ou athletico, antes esguio e rijo, arcabouço só músculos e ossos espáduas amplas". (VARZEA, 1935 : p. 2) O condicionamento "natural" de sua vocação militar, exposta na narrativa, foi completado por uma imagem que ilustra tais características [figura 2].

Figura 2 - Imagem de Bento Gonçalves

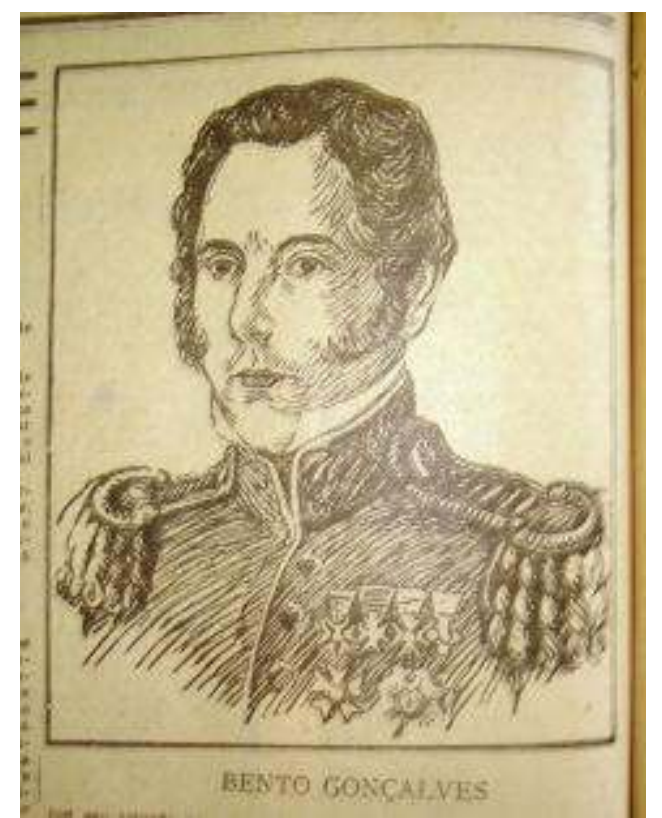

Publicada pelo jornal Diário de Notícias, Porto Alegre, 20 set. 1935, p. 20

Museu de Comunicação Social Hipólito José da Costa)

7 No Diário de Notícias, Antonio de Souza Netto foi lembrado por André Carrazzoni ${ }^{7}$ como o "chefe da famosa cavallaria que esculpiu no pampa rio-grandense os ageis grupos equestres das suas legiões de centauros (...)"*. (CARRAZZONI, 1935: p. 6) Tal qualidade foi mencionada no texto de Várzea, como algo inerente ao sul-rio-grandense, e que fazia de Bento Gonçalves "um perfeito gaúcho". (VARZEA, 1935 : p. 2) As figuras do militar e do estancieiro estão do mesmo modo presentes nas imagens que ilustram as capas das edições comemorativas do Diário de Notícia [figura 3] e do Correio do Povo [figura 4]9.

8 As pinturas publicadas pelos jornais citados trazem as assinaturas de dois pintores formados pela Escola Nacional de Belas Artes: Orózio Herculano Belém e Armando Vianna ${ }^{10}$. Nota-se que ambos os jornais empenhavam-se na realização de exemplares tão grandiosos quanto se pretendia que fosse a data centenária, e a apresentação dos trabalhos dos pintores vindos da capital do Brasil manifestam o valor das edições. 
Figura 3 - Capa da Edição Comemorativa do Primeiro Centenário da Revolução Farroupilha

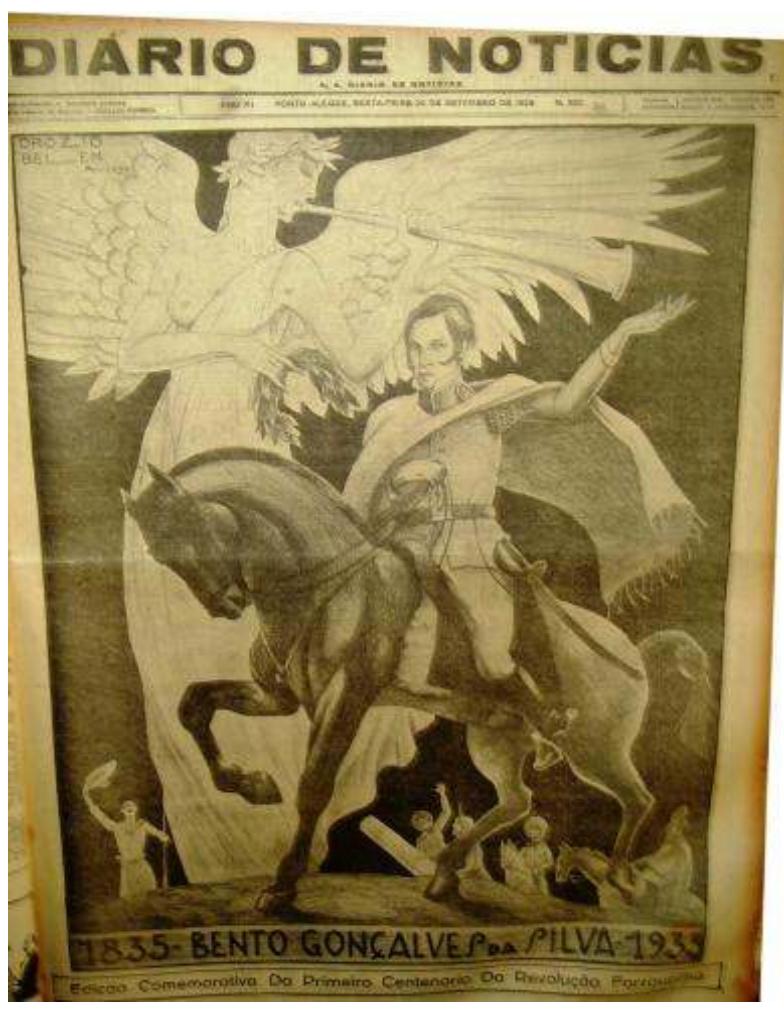

Publicada pelo jornal Diário de Notícias. Porto Alegre, 20 de setembro de 1935

Museu de Comunicação Social Hipólito José da Costa

9 Além da figura de Bento Gonçalves e da legenda que lembra os cem anos do episódio farroupilha, as gravuras apresentam outros pontos em comum, explicados pelas influências artísticas na Escola Nacional de Belas Artes. Conforme Mosani e Stori Jr., o ensino de desenho na referida instituição durante a segunda metade do século XIX, era orientado pelo Neoclassicismo francês. (MOSANER, 2007: p. 146) Dentre as características deste movimento, volta-se aqui para o retorno à concepção estética greco-romana. 
Figura 4 - Capa do Jornal Correio do Povo

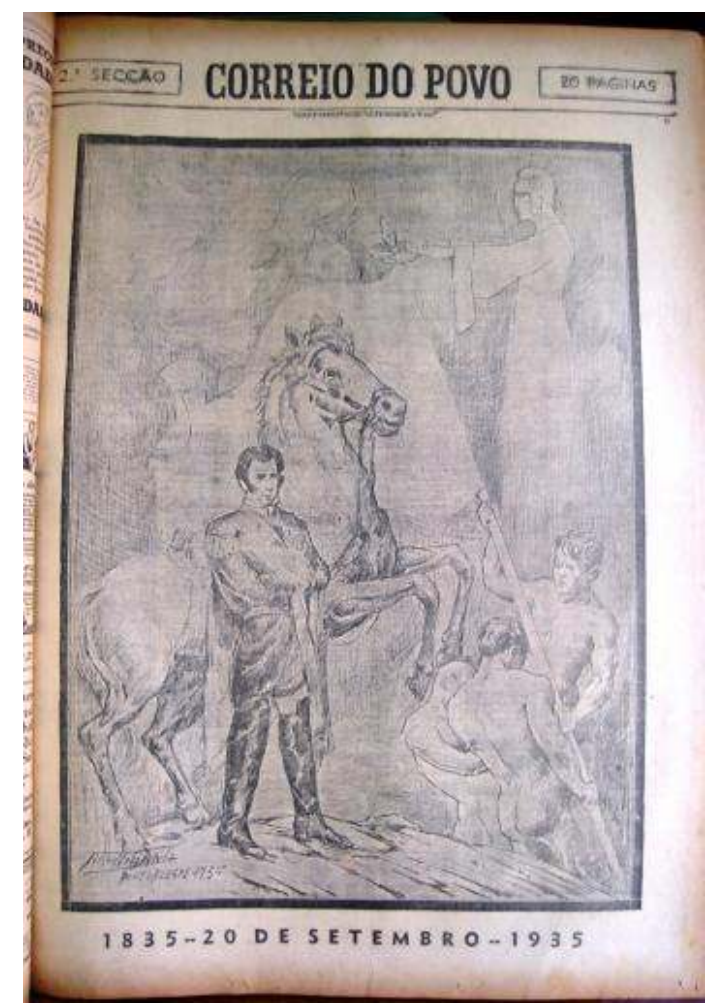

Porto Alegre, 20 de setembro de 1935, $2^{\text {a }}$ seção. (AHPAMV)

10 Observa-se que na edição do Correio do Povo, Bento Gonçalves está à frente de uma representação de Niké, deusa grega da vitória. A obra de Orózio Belém demonstra algumas semelhanças com uma das imagens já encontradas de Niké, localizada no Sítio Arqueológico de Éfeso. Como na escultura da Niké de Eféso, esta possui asas, carrega uma coroa de louros na mão, e tem o peito direito descoberto. o líder farroupilha, seguido pela deusa da vitória, está montado em um cavalo e vestindo uma farda militar. Homens usando lenços, chapéus e bombachas, também a cavalo, mas menores do que Bento Gonçalves, parecem aclamá-lo. A nudez, presente na imagem de Niké, foi também explorada no desenho de Armando Vianna. Ao lado Bento Gonçalves encontram-se três homens despidos, erguendo uma bandeira, possivelmente representando a República Rio-Grandense. Verifica-se aqui a figura de uma alegoria sobre a qual, embora se acredite tratar-se de uma referência a um deus grego, não se pode afirmar sua identificação exata. Sabe-se, no entanto, que uma coroa de louros, como a que ele aproxima da bandeira, era entregue aos vencedores dos jogos Píticos em honra ao deus Apolo, realizados em Delfos. Se o autor pretendia simbolizar a República Rio-Grandense com a bandeira que se erguia, sugere-se que Apolo entregava a coroa de louros para os "vitoriosos" farrapos. A narrativa visual composta pelas imagens cumpre determinada função pedagógica, fazendo lembrar e exaltando os heróis do passado, conforme se observa, também, nas narrativas textuais. Sem dúvida, este conjunto de representações foi criado a partir de questões colocadas pelo presente que rememorava a Revolução Farroupilha. Busca-se, neste sentido, perceber quais foram os usos do passado heroico dos farrapos. 


\section{Os heróis (do presente) : os sucessores farroupilhas reconhecidos pela imprensa}

11 Além das narrativas sobre os virtuosos heróis farroupilhas, os eventos em homenagem aos cem anos da epopeia ganharam espaço nas páginas dos jornais. Noticiários sobre as cerimônias ocorridas durante a programação da Exposição do Centenário Farroupilha destacaram a presença dos "ilustres chefes de governo" em bailes e jantares, frequentados por autoridades civis e militares. Dentre as atividades noticiadas, chama à atenção a publicação do jornal A Federação, referente ao banquete realizado no Casino Farroupilha. Ocupando o espaço de manchete do dia, a notícia deste evento se estendeu por toda a primeira página do jornal, apresentando, inclusive, as transcrições dos discursos pronunciados na ocasião do banquete. Ao centro da página, encontra-se o discurso do governador Flores da Cunha, e à sua direita, na parte inferior e com fonte menor, o pronunciamento do presidente Getúlio Vargas. Na mesma página, o texto " $O$ estadista que o Brasil não pode desconhecer", com fonte e espaçamentos diferenciados, tece comentários sobre o governador Flores da Cunha. (O ESTADISTA..., 1935 : p. 1)Flores da Cunha, em discurso publicado pelo Jornal da Manhã e A Federação, dedica a sua fala ao presidente Getúlio Vargas : "Quis V. Excia. Snr. Presidente da Republica, com a sua presença, revestir da mais significativa solenidade, a festa maxima do nosso Estado. [...] 0 amor á terra tinha de ser e foi, para maior alegria nossa, mais forte que os óbices decorrentes dos seus graves encargos, que bem poderiam te-lo afastado desta imponente celebração. Pelas mesmas razões é que o Rio Grande sempre esteve e estará com V. Exa., nas horas felizes e nos dias difíceis". Partindo do Rio Grande do Sul, como o lugar de origem de Getúlio Vargas, o governador resgata um vínculo entre a região e o presidente, e, através deste, requer o compromisso mútuo entre as partes. Neste intuito, ele lembra, ainda, do "Rio Grande de pé pelo Brasil" em uma clara referência à Revolução de 1930. (A EMPOLGANTE..., 1935 : p. 1)

12 Neste discurso, Getúlio Vargas surge como uma saída às "calamidades da demagogia e das humilhações do despotismo", inaugurando uma nova etapa na história do Brasil e do Rio Grande do Sul. Gradualmente, seguramente, o seu Governo foi reconstruindo o novo edificio politico, administrativo e economico do Brasil. Hoje, mercê de Deus desfrutamos da paz, da tranquilidade coletiva que permite ás energias do pais iniciarem uma época de trabalho $e$ prosperidades gerais". (A EMPOLGANTE..., 1935 : p. 1)

13 Ao encontro deste texto, um artigo publicado pelo Correio do Povo, sob a autoria de Victor Russomano ${ }^{11}$, distingue o contexto do centenário pelo "fato de estar no governo da República um gaúcho". Para o autor, o governo de Getúlio Vargas constituía um marco na história do Rio Grande, por romper com o "isolamento geographico e politico que afastou, por muito tempo, o Rio Grande de uma intervenção mais directa, no rumo dos negocios politicos do Paiz". (RUSSOMANO, 1935 : s/p) É possível notar que aqui há uma alusão à ideia de "vitimização" do Rio Grande do Sul, pois um dos argumentos que tentavam legitimar a Revolução Farroupilha recorria ao aspecto geográfico para afirmar a condição de esquecimento dos interesses da Província. Na mesma página do jornal A Federação, localiza-se o texto que tratou sobre o discurso proferido por Getúlio Vargas - também na ocasião do banquete -, e a sua visita ao Estado. Nota-se nesta narrativa algo semelhante ao que se indicou para o discurso de Flores da Cunha, concernente ao conceito de continuidade atribuído à figura do presidente: "S. Exa. que é decendente ilustre dos nossos mais gloriosos ancestrais, não poderia encontrar-se num posto mais condigno, 
qual seja o de chefe supremo da Republica, para presidir os festejos de uma época que consagra e glorifica uma geração de herois, cujo espirito republicano constituiu o seu mais intenso ideal de vida. Perfeitamente identificado com as nossas tradições e o nosso passado historico, e, profundamente ligado ao espirito republicano de seu povo, foi sempre S. Exa. um continuador do ideal dos batalhadores invictos de 35 e um realizador dos sonhos democráticos de Piratini".

O Rio Grande, assim, parecia viver em 1935 o resultado de um projeto iniciado há cem anos pelos "batalhadores invictos", protagonizado agora por Getúlio Vargas considerado herdeiro de uma estirpe heroica e do "espirito republicano" dos farrapos. (PRESIDENTE..., 1935 : p. 1)Como Flores da Cunha, Getúlio Vargas referiu-se à Revolução de 1930 em seu pronunciamento. No entanto, o texto do presidente apresenta outros aspectos a serem observados, relacionados à correspondência estabelecida entre os episódios de 1835 e 1930 : "Tenho bem vivo ainda o espetaculo memorável do Rio Grande, ao declarar-se de pé pelo Brasil, em 1930. Atravessavamos periodo que, sob muitos aspectos, repetia a situação politica de 1835. 0 regime se abastardara, desfigurado pelos corrilhos partidarios $e$ amolecido no seio das oligarquias imperantes. O caciquismo instalado no poder distribuia os beneficios publicos segundo a medida das preferencias domesticas. Em crise a economia da Nação, em crise a estrutura do regime, desesperava-se e ao mesmo tempo aneláva-se por uma reação saneadora.

Desprezando o comodismo das situações creadas, saltando sobre todas as conveniencias de ocasião, o povo riograndense ergueu-se de novo, como um só homem, para combater pela boa causa-pela causa que transformou o Brasil, de Norte a Sul, num campo de insurreição reivindicadora, tão expontanea e empolgante que ficará sendo o primeiro movimento em que a Nação pôde sentir-se a si mesma, em toda a plenitude da sua vitalidade civica, moça e impetuosa. (O NOTÁVEL..., 1935 : p. 1)

16 Para Getúlio Vargas, o Rio Grande revivia o passado farroupilha, em dois aspectos : na denúncia de um esquecimento da região, frente à repetição de uma política centralizadora ; e na designação sui generis, de "soldado" do Brasil. A comparação entre os dois eventos pressupõe uma ligação entre o passado e o presente, cujo elo se encontraria no pioneirismo sul-rio-grandense no cenário nacional. Desta forma, mais uma vez o Rio Grande participava de um movimento que contagiava todo país, como ocorrera durante o período regencial. Logo, assim como o passado farroupilha estava refletido no presente, este edificava o futuro da nação. O destino brasileiro, determinado pelo pioneirismo dos gaúchos em 1930, estava, portanto, consolidado em seu próprio governo: "Cinco anos já decorreram do memoravel acontecimento. Si outros beneficios não houvessem produzido, bastaria, para consagra-lo, esse despertar da conciencia nacional ante o descalabro da sua vida politica e economica. Mas, felizmente, neste curto espaço de tempo, já é possivel verificar a sadia repercussão que ele teve em todos os sectores da vida do pais, podendo-se afirmar que uma nova éra se abriu ao seu engrandecimento. [...]". (O NOTÁVEL..., 1935 : p. 1)Ao lado do discurso do presidente, um texto colocava em destaque o governador Flores da Cunha, cujo título anuncia a importância depositada em sua imagem : "O estadista que o Brasil não pode desconhecer". (O ESTADISTA..., 1935 : p. 1) Ao encontro do discurso de autoria do presidente Getúlio Vargas, esta narrativa institui uma conexão entre passado-presente-futuro, baseada na permanência das virtudes farroupilhas, personificadas na figura do governador ${ }^{12}$.

Flores da Cunha, compreendido por esta narrativa, representa o passado e o futuro do Rio Grande do Sul. Enquanto herdeiro das virtudes dos "velhos antepassados" farroupilhas, o governante parece ser predestinado à liderança da "sua terra" e do "seu 
povo", capaz de estar à frente dos sul-rio-grandenses na "marcha ascendente para seus objetivos eternos". Por outro lado, suas qualidades não se resumem apenas ao espírito legado pelos farrapos. Adaptado ao progresso em que se encontrava o Estado, Flores da Cunha surge como um "estadista moderno", inscrito no presente, por elevar a sociedade sul-rio-grandense ao desenvolvimento econômico e cultural, e, portanto, no futuro, por garantir a continuidade do projeto fundado em 1835. O destino anunciado pela narrativa inclui tanto os rumos do Rio Grande do Sul, como do Brasil, e em ambos se impõe a presença do governador, o qual "o Brasil não pode desconhecer". Cabe observar a pretensão de erguer a imagem de Flores da Cunha ao domínio nacional, manifestada na referência ao seu "espírito de brasilidade" e aos "altos destinos nacionais" reservados ao governador. Não se busca com isso constatar as aspirações do governador em âmbito nacional, mesmo porque o texto analisado seria insuficiente para fazê-lo. Interessa aqui perceber como o periódico valeu-se da comemoração e da memória farroupilha para responder aos embates em questão naquele momento. (O ESTADISTA..., 1935 : p. 1)No dia 20 de setembro, o Jornal da Manhã trouxe em sua primeira página uma imagem que apresenta algumas semelhanças com aquelas analisadas anteriormente. Em primeiro plano, nota-se um homem trajando uma bombacha e um lenço, portando uma bandeira e uma corneta, com a qual conclama outros tantos que o seguem a cavalo [figura 5]. No entanto, a mesma não apresenta qualquer referência à figura específica de Bento Gonçalves, como as imagens publicadas pelos jornais Diário de Notícias [figura 3] e Correio do Povo [figura 4]. Como enuncia o título que a acompanha, a representação se refere aos "Farrapos", que há cem anos orientavam o Rio Grande do Sul.

Figura 5 - Capa da Edição Farroupilha

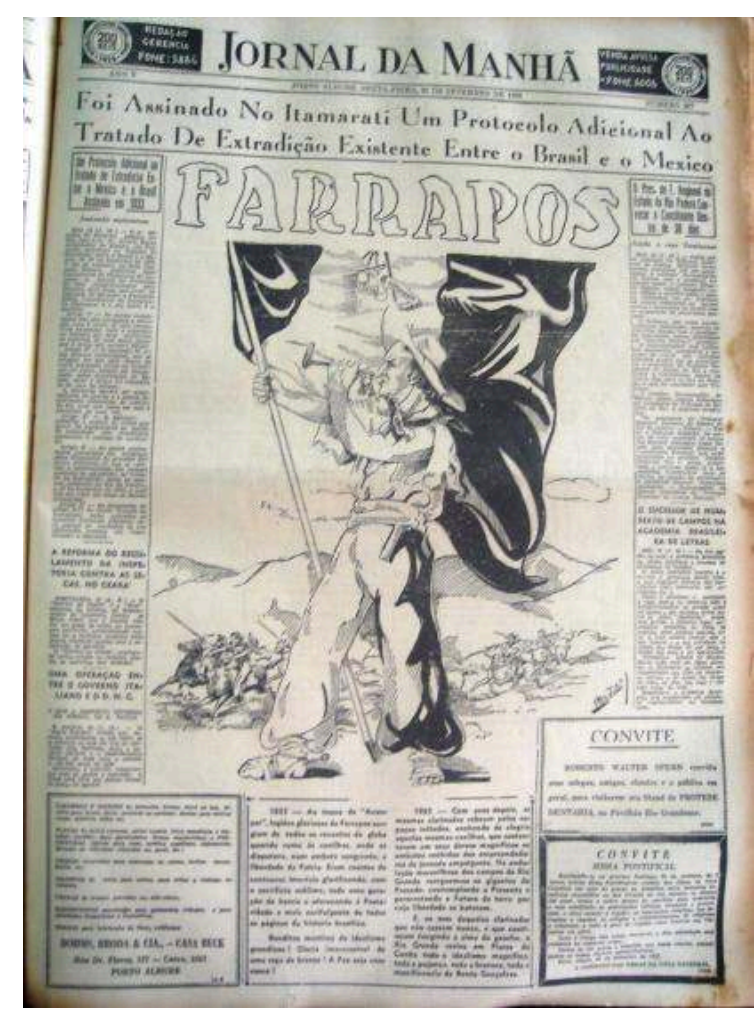

Publicada pelo Jornal da Manhã, Porto Alegre, 20 de setembro de 1935. (MCSHJC) 
O texto que segue esta imagem coloca 1835 e 1935 lado a lado ${ }^{13}$. Passado e presente entrelaçam-se na narrativa como um tempo único, ou, de acordo com Catroga, como um presente real, onde "entrecruzam-se heranças e expectativas". (CATROGA, 2001 : p. 28) A presentificação do passado farroupilha pode ser observada em pelo menos três aspectos : no território, na guerra, e no heroísmo de Bento Gonçalves. A paisagem das coxilhas, igualmente representada na imagem, simboliza a permanência da terra, marcada no passado e no presente pelo embate "sangrento" e "renhido" em nome da liberdade. Da mesma maneira, o heroísmo farrapo, preconizado em Bento Gonçalves, é atualizado em Flores da Cunha, assim como na imagem a seguir. Postos no mesmo nível, Flores da Cunha e Bento Gonçalves simbolizam o "presente" e o "passado" do Rio Grande do Sul [figura 6].

Figura 6 - Imagem do governador Flores da Cunha e do general Bento Gonçalves

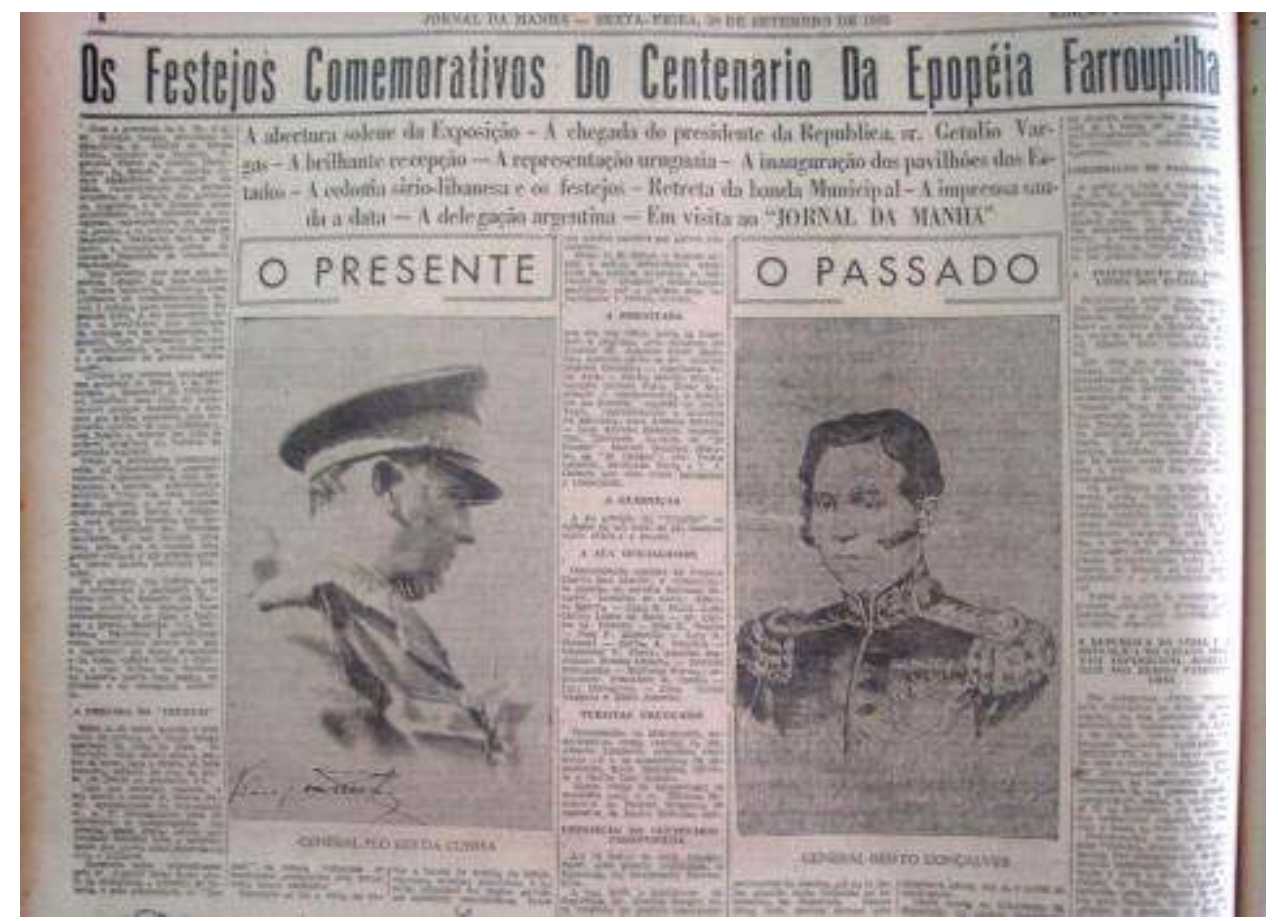

Publicadas pelo Jornal da Manhã, Porto Alegre, 20 de setembro de 1935, p. 6 (MCSHJC).

Se o passado manifestava-se em Flores da Cunha, sua imagem deveria estar de acordo com o "espírito brasileiro" dos farroupilhas. Assim tentava demonstrar o artigo "Um descendente dos Farrapos", publicado pelo jornal A Nação ${ }^{14}$, no Rio de Janeiro. (ESCOBAR, 1935 : p. 4) O mesmo jornal apresentava no ano anterior uma matéria, questionando a autoridade do governador sobre a bancada dos deputados rio-grandenses na Assembleia Constituinte. De acordo com Elíbio Jr., Adolfo Pinto, redator do Correio, enviou uma carta a Antunes Cunha, irmão de Flores da Cunha, alertando o governador sobre esta publicação. Segundo o historiador, "as intrigas se espraiavam da Câmara dos Deputados às redações de jornais minando o comando de Flores e que, em resposta, criava uma rede de informantes designados a delatar os inimigos". (ELÍBIO, 2003 : p. 122-123) Talvez o texto abordado a seguir, seja um esforço em restaurar o desgaste da imagem do governador, e não por acaso foi publicado em ambos os jornais.O centenário farroupilha, que poderia agitar ainda mais as polêmicas entre o poder nacional e estadual - se pensarmos no debate sobre o separatismo -, parece ter sido transformado 
em uma oportunidade para amenizar esta situação. Assim como nas narrativas anteriormente analisadas, Flores da Cunha aparece para o presente como um dos heróis do passado, e aqui, ainda mais claramente, como continuidade : "Descendente legitimo dos herois Farrapos, baluarte inquestionavelmente moral da raça que se agita nas coxilhas do sul, Flores da Cunha é um capricho atavico do destino que pôs nele toda a bravura impulsiva da geração dos gigantes de 35. Flores da Cunha, é pois um continuador !..." (ESCOBAR, 1935 : p. 4)Com isso, tenta-se sobrepujar as acusações feitas sobre o governador. As mesmas não passariam, então, de difamações daqueles que o cobiçam: "Como sempre a superioridade de um espirito e a elegancia de uma atitude desperta, em torno de si, uma avalanche de inveja, um caldear infinito de derrotismos inúteis". Segundo o texto, as atitudes "erroneamente interpretadas" do governador, eram, portanto, consequência de uma das suas qualidades: o excesso de franqueza. Outra qualidade apontada foi "o culto extremado das liberdades humanas, e a sua decidida indulgencia - prejudicial as vezes - ás leis demasiadamente liberais que regem o pais". (ESCOBAR, 1935: p.4)Não por acaso as narrativas sobre o governador Flores da Cunha, aqui analisadas, foram publicadas em $A$ Federação e no Jornal da Manhã. Ambas as instituições possuíam interesse nesta visão sobre Flores da Cunha, devido seus vínculos com o mesmo. Ângelo Flores da Cunha, irmão de Flores da Cunha, era proprietário do Jornal da Manhã, desde 1931. A Federação, que já havia sido o órgão oficial do PRR (Partido Republicano Rio-Grandense), passou a representar o PRL (Partido Republicano Liberal), desde a sua fundação (1932). Percebese, portanto, que a produção das narrativas sobre Flores da Cunha não esteve isolada da participação destes veículos nas disputas políticas. Ao contrário, compreende-se que, com o emprego de uma memória heroica sobre o passado farroupilha, os jornais $A$ Federação e o Jornal da Manhã trabalharam na construção de uma imagem positiva do governador.

\section{Considerações Finais}

20 A escolha de um herói, como alerta Carvalho, não ocorre no "vazio social". Ao contrário, ela "tem de responder a alguma necessidade ou aspiração coletiva, refletir algum tipo de personalidade ou de comportamento que corresponda a um modelo coletivamente valorizado". (CARVALHO, 1990 : p. 56) Diante do exposto, pode-se perceber que definir quais eram os heróis da revolução e conferir-lhes um lugar simbólico no passado da nação foi umas das preocupações das narrativas que exaltaram o caráter mítico dos farroupilhas. Ao registrarem os farrapos no passado nacional, as narrativas habilitaram o uso da memória destes heróis no presente. O espaço ocupado nos periódicos A Federação e no Jornal da Manhã pelos textos que enalteceram o presidente Getúlio Vargas e, ainda mais recorrentes, os que avultaram o governador Flores da Cunha, não se repetiu nos demais jornais analisados. $\mathrm{O}$ vínculo que ambos mantinham com o governador, e a ligação entre o primeiro - apesar da convergência política entre Flores e Vargas - e o presidente, assinalam o interesse pela memória dos personagens da revolução. Investindo-os com o mesmo "espírito" dos farroupilhas, as narrativas tentavam afirmar os líderes de um novo regime que, igualmente inspirado por estes ideais, continuavam a obra iniciada há cem anos. Por fim, cabe destacar a importância da ampliação dos estudos que investiguem o processo de construção da memória deste evento, tendo em vista o alcance das comemorações da Revolução Farroupilha e o lugar reservado a este episódio no imaginário sul-rio-grandense. Neste sentido, considera-se que entender como esta memória institucionalizou-se em determinados contextos seja tão 
fundamental quanto compreender o acontecimento em si mesmo. Talvez desta forma, ela possa ser percebida como o resultado de disputas, seleções, esquecimentos e conformações que cristalizaram para o presente uma interpretação sobre o passado.

\section{BIBLIOGRAFIA}

CARVALHO, José Murilo de. A formação das almas : o imaginário da República no Brasil. São Paulo : Companhia das Letras, 1990, p. 56.

ELÍBIO JR., Antônio Manoel. A construção da liderança política de Flores da Cunha : governo, história e política (1930-1937). 2006. 430 p. Tese (Doutorado em História) - Programa de Pós-Graduação em História. Universidade Estadual de Campinas, Campinas, SP, 2006.

ELMIR, Cláudio Pereira. A História devorada. Nos rastros dos crimes da Rua do Arvoredo. Porto Alegre : Escritos Editora, 2004.

FERREIRA, Marieta de Morais. A Nação. Disponível em : http://cpdoc.fgv.br/acervo/ arquivospessoais. Acesso em : 18/02/2012.

GONZÁLES, Juan Sanchéz. Sobre la memória. El passado presente en los medios de comunicación. Historia Actual Online, Cádiz, n. 4 : 153-163, 2004. Disponível em : http://www.historia-actual.org. Acesso em : 21/04/2011.

MARTINS, Ari. Escritores do Rio Grande do Sul. Porto Alegre : Editora da UFRGS, 1978.

PESAVENTO, Sandra Jatahy. A invenção da Sociedade Gaúcha. Ensaios FEE, Porto Alegre, v. 14, n. $2: 383-396,1993$.

RÜDIGER, Francisco. Tendências do Jornalismo. Porto Alegre : EDUFRGS, 1993. 141 p.

SCHEIDT, Eduardo. O processo de construção da memória da Revolução Farroupilha. Revista de História, São Paulo, USP, n.147 :189-209, 2002.SILVA, Camila. Do passado ao futuro : a escrita comemorativa do Centenário Farroupilha na imprensa porto-alegrense. Dissertação (Mestrado em História) - Programa de Pós-Graduação em História. Universidade do Vale do Rio dos Sinos, São Leopoldo, 2012.

\section{Periódicos}

A EMPOLGANTE oração de ontem do Gal. Flores da Cunha. A Federação, Porto Alegre, 23 set. 1935, p. 1. CALMON, Pedro. Heróes e Terra. Correio do Povo, Porto Alegre, 20 set. 1935, s/p (Edição Farroupilha).

CARRAZZONI, André. Mythos, symbolos, legendas. Correio do Povo, Porto alegre, 8 set. 1935, p. 6. ESCOBAR, Rui. Um descendente dos Farrapos. Jornal da Manhã, Porto Alegre, 22 out. 1935, p. 4. FARRAPOS. Jornal da Manhã, Porto Alegre, 20 set. 1935, p. 1.

O ESTADISTA que o Brasil não pode desconhecer. A Federação, Porto Alegre, 23 set. 1935, p. 1.0 NOTÁVEL discurso do chefe da nação no banquete. A Federação, Porto Alegre, 23 set. 1935, p. 1. 
PRESIDENTE Getulio Vargas. A Federação, Porto Alegre, 19 set. 1935, p. 1.

REICHARDT, H. Canabarro. Bento Gonçalves : a ação - o militar. Diário de Notícias, Porto Alegre, 20 set 1935, p. 20. ROSA, Othelo. David Canabarro. Diário de Notícias, Porto Alegre, 20 set. 1935 (2 secção), s/p.

RUSSOMANO, Victor. Os farrapos, pioneiros do constitucionalismo republicano no Brasil. Correio do Povo, Porto Alegre, 20 set. 1935, s/p (Edição Farroupilha).

VARZEA, Virgilio. Bento Gonçalves. Correio do Povo, Porto Alegre, 20 set. 1935, p. 2.

VULTO da epopeia farroupilha. Manduca Carvalho. Diário de Notícias, Porto Alegre, 20 set. 1935, p. 5.

\section{NOTAS}

1. Para Pesavento: "É por todos sabido que existe um estereótipo sobre o Rio Grande do Sul, sobre os gaúchos e sobre a região sulina”. Partindo deste pressuposto, tentaremos problematizar a questão da construção da identidade gaúcha e suas teceduras com a rememoração da Revolução Farroupilha. (PESAVENTO, 1993 : p. 383)

2. Ao utilizar esta expressão, Elmir está se referindo à uma suposta "autonomia do objeto", geralmente praticada por uma historiografia positivista. (ELMIR, 2004 : p. 23)

3. Em estudo dedicado às celebrações da Revolução Francesa, Ozouf chama a atenção para a função pedagógica da festa, pois, por meio desta, uma "história anual e comemorativa da Revolução" é ensinada "àqueles que não a conheceram diretamente". A autora verificou a importância atribuída aos jornais como "fundadores da memória de um povo", destacando que "o texto e a palavra são obstinadamente encarregados de reaver tudo". (OZOUF, 1988 : p. 219)

4. No mesmo sentido, Gonzáles aponta a importância das comemorações de "acontecimentos históricos relevantes", por tratarem-se de ocasiões propícias para a elaboração de novas leituras e interpretações do passado que, em consonância com o tempo vivido, chegam às páginas dos periódicos como ideias e indicações de inquestionável interesse para os historiadores. (GONZÁLES, $2004:$ p. 156)

5. Para o historiador : "Revisitar o passado não pode ser desvinculado das demandas e exigências de um tempo presente e, nesse sentido, sua compreensão é também parte da inteligibilidade de uma cultura histórica que aciona experiências, imagens e atores do passado para uma contemporaneidade que busca nesse tempo que ficou para trás referências para imaginar o mundo em que vive". (GUIMARÃES, 2007 : p. 39)

6. Vírgilio Varzea foi articulista da Gazeta Carioca, e membro do IHGSC.

7. Cursou a Faculdade de Direito de São Paulo, e iniciou seu trabalho como jornalista no periódico A Elite, em Quaraí. Foi redator dos jornais Diário de Notícias, Correio do Povo e Jornal da Tarde, em Porto Alegre ; e nos jornais O Radical, A Noite, A Hora e Folha Carioca, no Rio de Janeiro. (MARTINS, 1978 : p. 130)

8. 0 "centauro", conforme destaca Pesavento, esteve historicamente vinculado ao ethos gaúcho. (PESAVENTO, 1993 : p. 388) Para Zalla, a figura do centauro, formada pela união do homem e do cavalo, "simboliza a simbiose do peão e do animal na Pampa Gaúcha, expressando um arquétipo utilizado pela literatura especializada desde o século XIX : o gaúcho a cavalo". (ZALLA, 2010 : p. 18)

9. Cabe aqui destacar a análise de Zalla sobre a trajetória intelectual e a obra de Luiz Carlos Barbosa Lessa. Dentre os momentos da biografia histórico-intelectual do tradicionalista sul-riograndense, o historiador trata das representações sociais sobre a figura do gaúcho, manifestadas por alguns estudantes do Colégio Júlio de Castilhos, entre eles João Carlos Paixão Côrtes e Barbosa 
Lessa : "Simbolicamente, a primeira atividade do grupo, o qual começara a se articular cerca de um mês antes como um 'Departamento de Tradições Gaúchas' do Grêmio Estudantil do 'Julinho', que viria a se constituir em seu primeiro rito específico regular, incorporado oficialmente em 1964 ao calendário de efemérides do Estado como 'Semana Farroupilha', sintetiza as duas figuras privilegiadas nos discursos regionalistas, literários e historiográficos, precedentes : o militarestancieiro, conquistador do território, defensor das fronteiras e, devido ao episódio farroupilha, esteio da liberdade e da república, e o campesino, arraia miúda das tropas dos generais, mas, e principalmente, povoador dos descampados, peão e lavrador, construtor do Rio Grande, fundamento da economia e origem da cultura regional". (ZALLA, 2010 : p. 145)

10. Sobre o trabalho dos artistas, ver em : ENCICLOPÉDIA Itaú Cultural. Disponível em : http:// www.itaucultural.org.br/aplicexternas/enciclopedia_ic/index.cfm?fuseaction=artistas. Acesso em : 17/10/2011.

11. Victor Russomano formou-se na faculdade de Medicina do Rio de Janeiro e na Faculdade de Direito de Pelotas. Foi membro do IHGRS e da Academia Rio-Grandense de Letras. (MARTINS, 1978 : p. 511)

12. "O magistral discurso do Governador do Estado, no momento em que o Rio Grande dava inicio aos festejos comemorativos do primeiro Centenario Farroupilha e inaugurava, ao mesmo tempo, a maior demonstração já realizada do seu extraordinário progresso, veio completar, magnificamente, a grande hora civica que está vivendo o Estado, porquanto assim pode demonstrar que seu governante é um homem que sente agudamente as vibrações da coletividade que dirige e, por consequencia, pode guia-la com alta visão administrativa e politica, para os altos destinos nacionais que lhe estão reservados. Amando sua terra acima de tudo, confundido profundamente com o seu povo nas horas dramaticas que ele tem vivido, como tambem nos seus momentos de alegria radiosa e feliz, o grande condutor demonstrou ainda, em seu discurso inaugural, essa consciencia historica, esse conhecimento profundo do passado de sua terra, sem o qual não se pode conceber um homem de governo capaz de conservar e desenvolver uma fulgurante civilização em marcha ascendente para seus objetivos eternos. O Rio Grande do Sul que desfila nessa parada monumental das suas forças produtivas, das suas industrias, do seu comercio, da sua agricultura, da sua pecuária e das suas artes, o grande certame organizado sob o rigor de uma admiravel técnica moderna, o luxo e a beleza dos seus stands impressionantes, e principalmente o profundo espirito de brasilidade que preside os menores detalhes de sua organização, - exprime, ao mesmo tempo, o admiravel grau de cultura a que atingimos e a dinamica vontade de um governo que não encontra obstaculos para a realisação de um programa administrativo que vem executando com uma precisão e uma tenacidade dignas da maior admiração. Convem não esquecer, portanto, e antes proclamar bem alto e sempre, que se o Rio Grande foi uma surpreendente revelação para muitos espiritos que ainda o desconheciam, ou não o queriam conhecer, - á frente de seus destinos se encontra a figura singular de um homem que, tendo as mesmas virtudes primaciais dos velhos antepassados cuja memoria sabe cultuar, sublimou-as, entretanto, no sentido das realidades presentes, creando assim um tipo de estadista moderno - culto, orientado, corajoso e energico, - que já agora o Brasil não póde desconhecer". (O ESTADISTA..., 1935 : p. 1)

13. “1835 - Ao toque de "Avançar", legiões gloriosas de Farrapos surgiam de todos os recantos da gleba querida rumo ás coxilhas, onde se disputava, num embate sangrento, a liberdade da Patria. Eram cortes de centauros imortais glorificando, com o sacrificio sublime, toda uma geração de herois e oferecendo á Posteridade a mais aurifulgente de todas as paginas da historia brasílica. Benditos martires do idealismo grandioso ! Gloria inacessivel de uma raça de bravos ! A Paz seja convosco! 1935 - Cem anos depois, as mesmas clarinadas reboam pelos espaços infindos, enchendo de alegria aquelas mesmas coxilhas, que sustentaram em seus dorsos magnificos os embates renhidos dos empreendedores da jornada empolgante. Na ondulação maravilhosa dos campos do Rio Grande reerguem-se os gigantes do Passado, contemplando o Presente e 
perscrutando o Futuro da terra por cuja liberdade se bateram. E, ao som daquelas clarinadas que não cessam nunca, e que continuam tangindo a alma do gaucho, o Rio Grande revive em Flores da Cunha todo o idealismo magnifico, toda a pujança, toda a bravura, toda a munificiencia de Bento Gonçalves". (FARRAPOS, 1935 : p. 1)

14. O jornal A Nação foi fundado em 1933, por José Soares Maciel Filho e João Alberto Lins de Barros, então chefe de polícia do Distrito Federal. Conforme Marieta de Morais Ferreira, João Alberto, preocupado em criar uma imprensa favorável ao governo de Getúlio Vargas, apoiou a criação deste periódico, destinado às classes médias urbanas. (FERREIRA, S.l.)

\section{RESUMOS}

O presente artigo analisa um conjunto de textos publicados pela imprensa periódica portoalegrense, na ocasião do Centenário da Revolução Farroupilha (1935). O estudo insere-se nos debates sobre o trabalho da memória e os usos do passado, por meio dos quais se discute os elementos que colaboraram na representação do heroísmo farroupilha e na identificação dos farrapos com os heróis do presente. Considerando a rememoração como o diálogo de um determinado presente com o passado, assim como a forma pela qual o primeiro inscreve-se no transcuro temporal, procura-se refletir sobre os significados da atualização do passado para a contemporaneidade tratada. Desta forma, pretende-se contribuir para os estudos sobre a construção da memória de um dos episódios mais repercutidos na sociedade sul-rio-grandense.

Cet article analyse un ensemble de textes publiés par la presse périodique de la ville de Porto Alegre, à l'occasion du Centenaire de la Révolution Farroupilha (1935). L'étude s'insère dans les débats à propos du travail de la mémoire et les usages du passé, à travers lesquels on discute les éléments qui ont collaboré à la représentation de l'héroïsme farroupilha et à l'identification des farrapos avec les héros du présent. En tenant compte de la remémoration comme dialogue d'un présent déterminé avec le passé, et aussi comme forme par laquelle le premier s'inscrit dans le temps qui passe, on cherche à réfléchir sur les significations de l'actualisation du passé pour la contemporanéité traitée. De cette façon, on a l'intention de contribuer aux études qui traitent de la construction de la mémoire de l'un des épisodes qui a eu une très grande répercussion dans la société de Rio Grande do Sul.

\section{ÍNDICE}

Palavras-chave: Centenário Farroupilha, comemoração, imprensa, memória e usos políticos do passado

Mots-clés: Centenaire de la Révolution Farroupilha, commémoration, presse, mémoire et usages politiques du passé 


\section{AUTOR}

\section{CAMILA SILVA}

Autora da dissertação intitulada "Do passado ao futuro : a escrita comemorativa do Centenário Farroupilha na imprensa porto-alegrense", concluída em 2012. Apoio da CAPES.

Mestre em História pela Universidade do Vale do Rio dos Sinos

camila_historia[at]yahoo.com.br 